\title{
An assessment of post-harvest fish losses and preservation practices in Siavonga district, Southern Zambia
}

\author{
Sahya Maulu ${ }^{1,2^{*}}$ D, Oliver J. Hasimuna ${ }^{3,4}$, Concilia Monde $^{4}$ and Malawo Mweemba ${ }^{4}$
}

\begin{abstract}
Fish is an extremely perishable food product which requires proper handling soon after harvest. The present study was aimed at assessing post-harvest fish losses and preservation practices in Siavonga district, Southern Zambia. Structured and semi-structured questionnaires were used to collect data on post-harvest fish losses and preservation practices from aquaculture producers, artisanal, and commercial fishers. All the fishers who landed on the lakeshore were interviewed, while aquaculture producers were randomly selected based on the information provided by the local department of fisheries. The results of the study revealed that all the fishers experienced post-harvest fish losses at varying degrees with those losing up to $10 \%$ of the total catch being in the majority. In contrast, aquaculture producers did not report any post-harvest fish losses. Most aquaculture producers commonly used chilling as preservation practice contrary to artisanal and commercial fishers who commonly used smoking and sun sun-drying respectively. Furthermore, fish product safety and quality control were poorly practiced in the district. Lack of cold storage facilities and fluctuating weather conditions were the major challenges impacting fish post-harvest activities. Therefore, to curb the loss of revenue due to post-harvest fish losses, we propose the introduction of new technology, self-development skills for fishing communities, and enhanced access to refrigeration facilities.
\end{abstract}

Keywords: Fisher, Aquaculture production, Post-harvest, Losses, Preservation practice

\section{Introduction}

Fish has consistently been among the most commonly used and comparatively cheaper source of animal protein for most people across the globe. In most developing countries, fish is often the key source of animal protein and a source of direct and indirect employment opportunities to rural communities. Fish post-harvest activities within the fisheries value chain have often received less attention in rural community development programs despite them being a critical component of the livelihood structure (Kitinoja, 2016; Lokuruka, 2016). However, fish deserve more attention in food policies than it currently receives owing to its importance in the

\footnotetext{
* Correspondence: sahyamaulu@gmail.com

${ }^{1}$ Centre for Innovative Approach Zambia (CIAZ), Lusaka, Zambia

${ }^{2}$ Wuxi Fisheries College, Nanjing Agricultural University, Wuxi, China

Full list of author information is available at the end of the article
}

food basket, unique nutritional characteristics, and higher production efficiency compared with other forms of agricultural systems (FAO, 2004; Subasinghe, 2016). Fish and fish products currently constitute the most traded food products globally (Food and Agriculture Organization (FAO), 2018). Significant improvements in fish trade for both local and international markets largely depend on the quality of fish post-harvest activities in the fisheries sector. Globally, fish losses are estimated to be ten to twelve million tons per year, accounting for around ten percent $(10 \%)$ of the total production from capture fisheries and aquaculture (Ward and Signa, 2017). Hence, the fight against hunger requires more than just increasing production and total food supply but also improving food systems, a full understanding of the local conditions and factors affecting the value chains for the products, and more attention to

(c) The Author(s). 2020 Open Access This article is licensed under a Creative Commons Attribution 4.0 International License, which permits use, sharing, adaptation, distribution and reproduction in any medium or format, as long as you give appropriate credit to the original author(s) and the source, provide a link to the Creative Commons licence, and indicate if changes were made. The images or other third party material in this article are included in the article's Creative Commons licence, unless indicated otherwise in a credit line to the material. If material is not included in the article's Creative Commons licence and your intended use is not permitted by statutory regulation or exceeds the permitted use, you will need to obtain permission directly from the copyright holder. To view a copy of this licence, visit http://creativecommons.org/licenses/by/4.0/. 
the barriers limiting investment in improved postharvest handling practices, technologies, and policy (Kitinoja, 2016).

In Zambia, fish is an important food item that accounts for up to $55 \%$ of the national dietary animal protein (Global Fish Alliance (GFA), 2007). Although the country's current annual fish production is estimated at 120,000 tones from both capture fisheries and aquaculture, there is still a continued importation of fish to cover domestic deficit (Maulu et al., 2019). The massive freshwater and land resources coupled with available human capital increase the potential for Zambia to increase its fish and fish products output. Furthermore, deliberate investment into minimizing or where possible complete elimination of post-harvest food losses could significantly minimize the gap between supply and demand (Onyango et al., 2017; Getu et al., 2015). However, achieving this requires a clear understanding of postharvest activities and preservation practices by the producers in target areas. In Zambia, generally, information on post-harvest fish losses among various players in the fisheries sector is still largely unclear. Moreover, the limited literature available has only focused on production from capture fisheries, leaving the output from aquaculture unaccounted for.

Siavonga district is one of Zambia's major aquacultureproducing district and among the country's major fishery community. Lake Kariba in this district harbors the country's largest aquaculture-producing companies mainly in cages (Hasimuna et al. 2019). Because of its high potential for fish production both in fishing and aquaculture production activities, the district has continued to receive a large proportion of fishers from other low fish producing fisheries annually (Maulu and Musuka, 2018). These fisheries and aquaculture activities, such as artisanal and commercial fishing, cage and pond aquaculture production, fish trade, and animal feed manufacturing in Siavonga, could attract future development in food security and economic development. Therefore, the aim of this study was to investigate post-harvest fish losses and preservation practices in Siavonga district in the southern part of Zambia.

\section{Materials and methods \\ Study site}

Siavonga district is situated along stratum IV of Lake Kariba on the north shore in the Southern Province of Zambia (16' 32' S 28' 43' E/16.533' S 28.717' E). Formed in the 1950s from damming the Zambezi River, Lake Kariba is ranked the largest man-made lake by volume in the whole world. Soon after its creation, the lake was stocked with fish and is currently being controlled as a shared fishery between Zambia and Zimbabwe (Fig. 1). For the purpose of management, Lake Kariba on the Zambian side was divided into four strata (I, II, III, IV), with stratum IV being the most important in the country for both fisheries and aquaculture activities. The 2010 Zambian Census of Population and Housing estimated the population of Siavonga district to be 90,213 people with fishing being the main economic activity of the people. Recently, the lake has increasingly received a large number of fishers from other fisheries where fish catches are deemed to have significantly declined over the years (Maulu and Musuka, 2018).

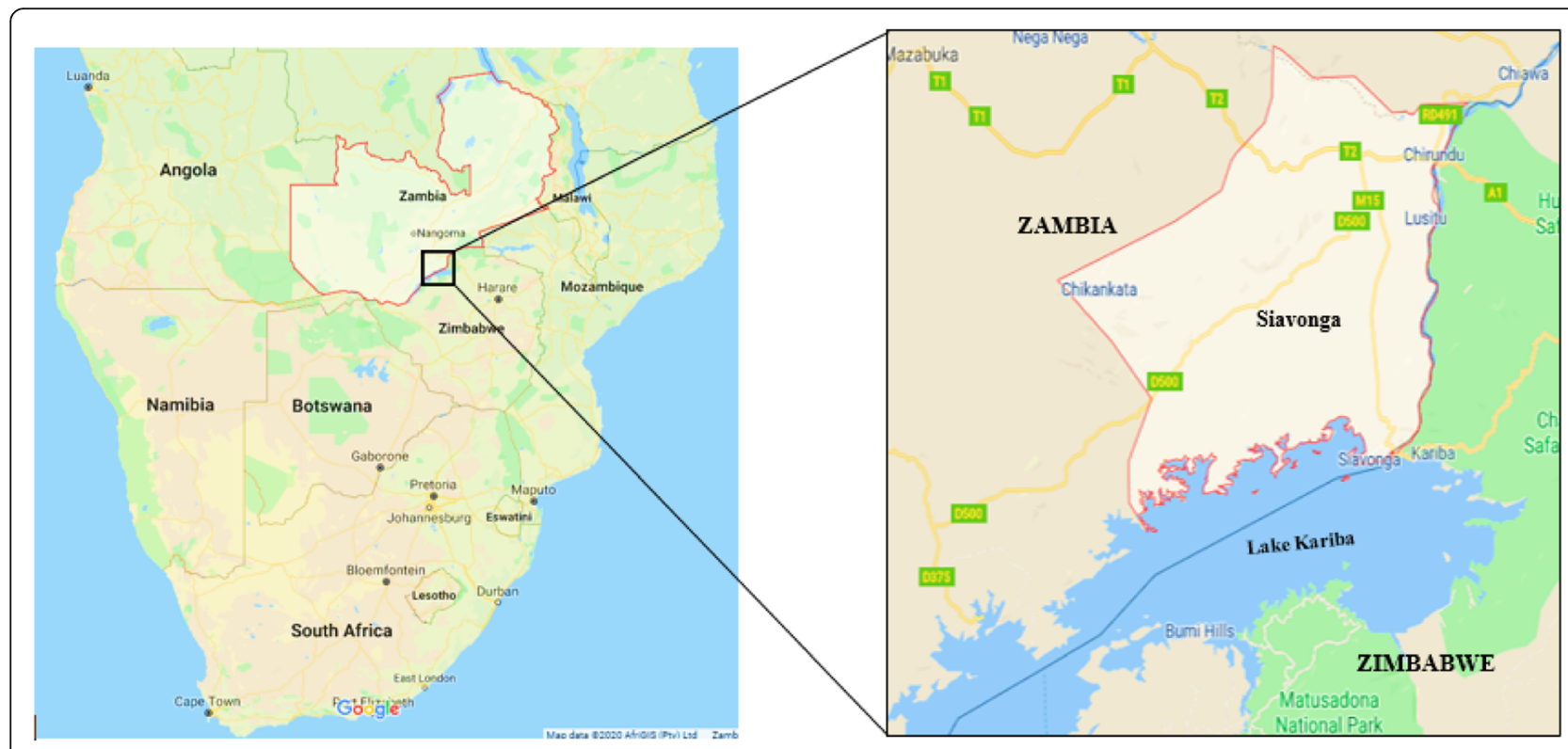

Fig. 1 Map showing the geographical location of Siavonga district along Lake Kariba 


\section{Study area overview of fisheries and aquaculture activities}

According to the Zambian Department of Fisheries (DoF) annual report (2017), Siavonga district along Lake Kariba has a total of 101 approved companies involved in the commercial fishery. Our recent review of aquaculture production in Zambia showed that approximately $79 \%$ of the total aquaculture production (approximately 32,888 tons annually) in the country is supplied by large-scale commercial producers of which the majority comes from cage aquaculture in Siavonga district (Maulu et al., 2019). Compared with commercial fishery, artisanal fishery in the district is poorly documented which makes effective management difficulty. However, efforts were made to capture as many fishers as possible. In this study, six major landing sites for artisanal fishers were identified along Lake Kariba in Siavonga district. Information regarding aquaculture production provided by the local DoF in Siavonga showed that there were about 15 recorded aquaculture producers in the district of which 13 were investigated in this study.

\section{Study design and data collection}

Three sets of questionnaires were designed and used for data collection in this study. The first set was designed for the Department of Fisheries (DoF) officers and aimed at obtaining demographic information about the fishers and aquaculture producers in the district and to get an indication of the best time to meet them for interviews and information on postharvest activities. The second set was designed for the fishers (commercial and artisanal) to obtain information on the fish catches, losses, and preservation practices. The third set targeted the aquaculture producers in the district to gather information on their fish post-harvest losses and preservation practices. The main information sought in the questionnaires were (1) how is post-harvest fish losses in Siavonga district? (2) Are there strategies used to minimize post-harvest losses by the fishers and aquaculture producers? (3) What practices are used to preserve fish by the fishers and aquaculture producers? (4) How effective are the practices used? (5) Are the producers observing any fish product safety and quality control guidelines? And (6) what are some of the major challenges contributing to postharvest fish losses in the district? Questionnaires were pre-tested prior to data collection and necessary adjustments were made to improve them. All the fishers who landed on Kariba lakeshore in the district during the data collection period were included in the target population. The estimated total number of aquaculture producers in the district was obtained through the local department. Daily (except Saturdays) visits were made to various landing sites around the Lake within Siavonga district from 06:00 am to 4:00 pm in the months January to March 2018 following advice from the DoF.

\section{Data analysis}

In order to draw inferences from the collected data, Statistical Package for Social Scientists (SPSS) for Windows version 22.0 was used for analysis to generate descriptive (percentage) statistics. Patterns and trends in the postharvest losses, preservation practices, and challenges thereof were obtained through summarizing data into frequency tables, charts, and graphs created using SPSS alongside Microsoft Excel.

\section{Results \\ Post-harvest fish losses}

The results of post-harvest fish losses experienced by fishers and aquaculture producers in Siavonga district are indicated in Table 1 . As shown in the table, of the total interviewed population $(n=121), 40.49 \%$ were artisanal fishers, $48.76 \%$ were commercial fishers, and only $10.74 \%$ represented the aquaculture producers. All the fishers (artisanal and commercial) indicated that they were experiencing some degree of post-harvest fish losses during their activities, while the aquaculture producers did not report any postharvest fish losses. Among those that experienced post-harvest fish losses, $79.59 \%$ and $81.36 \%, 10.20 \%$ and $7.78 \%, 4.08 \%$ and $6.78 \%, 2.04 \%$ and $1.69 \%$, and $4.08 \%$ and $1.69 \%$ of those involved in the artisanal fishery and commercial fishery lost up to $10 \%, 10-$ $20 \%, 20-30 \%, 30-40 \%$, and $40-50 \%$ fish per given total catch respectively.

\section{Strategies employed to minimize post-harvest fish losses in Siavonga district}

The various strategies employed by the fishers and aquaculture producers to minimize post-harvest fish losses in Siavonga district are indicated in Table 2. As indicated in the table, $30.61 \%, 20.34 \%$, and $38.46 \%$; $57.14 \%, 44.07 \%$, and $38.46 \% ; 8.16 \%, 18.64 \%$, and $7.69 \%$; and $4.08 \%, 16.95 \%$, and $15.38 \%$ of those involved in the artisanal fishery, commercial fishery, and aquaculture production employed quick processing/preservation; quick selling while fresh; others (unspecified); and none strategies to minimize postharvest fish losses respectively. Overall, and based on each category, the most common strategy used by fish producers in Siavonga district was quick selling while the fish is still fresh. 
Table 1 Information on post-harvest fish losses by three categories of fish producers in Siavonga district

\begin{tabular}{|c|c|c|c|c|}
\hline \multirow[t]{2}{*}{ Factors } & \multicolumn{3}{|l|}{ Category } & \multirow[t]{2}{*}{ Total, $n(\%)$} \\
\hline & Artisanal fishery & Commercial fishery & Aquaculture production & \\
\hline Representation in the sample, $n(\%)$ & $49(40.49)$ & $59(48.76)$ & $13(10.74)$ & $121(100.00)$ \\
\hline Victims of post-harvest fish losses, $n(\%)$ & $49(100.00)$ & $59(100.00)$ & $0(0.00)$ & $108(100.00)$ \\
\hline Estimated loss (\% loss/catch): $\leq 10, n(\%)$ & $39(79.59)$ & $48(81.36)$ & $0(0.00)$ & $87(80.56)$ \\
\hline $10-20, n(\%)$ & $5(10.20)$ & $4(7.78)$ & $0(0.00)$ & $9(8.33)$ \\
\hline $20-30, n(\%)$ & $2(4.08)$ & $5(6.78)$ & $0(0.00)$ & $7(6.48)$ \\
\hline $30-40, n(\%)$ & $1(2.04)$ & $1(1.69)$ & $0(0.00)$ & $2(1.85)$ \\
\hline $40-50, n(\%)$ & $2(4.08)$ & $1(1.69)$ & $0(0.00)$ & $3(2.78)$ \\
\hline Total, n (\%) & 49 (100.00) & $59(100.00)$ & $0(0.00)$ & $108(100)$ \\
\hline
\end{tabular}

\section{Post-harvest fish preservation practices and their effectiveness}

The fish preservation practices used by the artisanal fishers, commercial fishers, and aquaculture producers in Siavonga district are shown in Table 3. 57.14\%, $0.00 \%$, and $7.69 ; 28.57 \%, 8.47 \%$, and $69.23 ; 8.16 \%$, $77.97 \%$, and $0.00 \% ; 6.12 \%, 13.56 \%$, and $23.08 \%$ of the artisanal fishers, commercial fishers, and aquaculture producers in Siavonga district commonly used smoking, chilling, sun sun-drying, and freezing as fish preservation practices respectively. Hence, smoking, chilling, and sun sun-drying were the most commonly used practice by the artisanal fishers, commercial fishers, and aquaculture producers respectively. In addition, the results showed that freezing was the commonly used practice as an alternative.

When the respondents were asked to rate the effectiveness of the preservation practices they were using based on a scale: effective, very effective, and not effective, the majority $(85.12 \%)$ reported that the practices were very effective, while the rest (14.88\%) indicated that they were effective Table 4. Furthermore, $83.67 \%$ of the artisanal fishers rated the practices as effective while $16.33 \%$ rated them as very effective; $84.75 \%$ of the commercial fishers said the practices were effective while the remaining $15.25 \%$ rated them as very effective, and $92.31 \%$ of the aquaculture producers rated the practices as effective with only $7.69 \%$ rating them as very effective.

\section{Fish product safety and quality control}

Table 5 indicates the results of the information on fish product safety and quality control prior to selling or consumption in Siavonga district. As shown in the table, only $42.15 \%$ of the fish producers in Siavonga district reported that they were observing some fish product safety and quality control regulations while the rest $57.85 \%$ were not. The majority $(53.06 \%)$ of those involved in the artisanal fishery were not observing any regulation, and only $46.94 \%$ indicated that they were observing some regulation of which $26.09 \%$ were observing internal (individual/company) regulation, $21.74 \%$ were observing external (local authority) regulation, and the majority $(52.17 \%)$ did not disclose the source or enforcer of regulations they were observing. Among the commercial fishers, only 33.90\% were observing some regulation related to product safety and quality control; from this percentage, $20.00 \%$ were observing internal regulation; $10.00 \%$ were observing regulations enforced by local authorities while the majority $(70.00 \%)$ did not provide information on the source of regulation they observed. For the aquaculture producers, the majority (61.54\%)

Table 2 Strategies employed by fish producers in Siavonga district to minimize post-harvest fish losses

\begin{tabular}{|c|c|c|c|c|}
\hline \multirow[t]{2}{*}{ Strategy } & \multicolumn{3}{|l|}{ Category } & \multirow[t]{2}{*}{ Total, $n(\%)$} \\
\hline & Artisanal fishery & Commercial fishery & Aquaculture production & \\
\hline Quick processing/preservation, $n(\%)$ & $15(30.61)$ & $12(20.34)$ & $5(38.46)$ & $32(26.45)$ \\
\hline Quick selling while fresh, $n(\%)$ & $28(57.14)$ & $26(44.07)$ & $5(38.46)$ & $59(48.76)$ \\
\hline Others (unspecified), $n$ (\%) & $4(8.16)$ & $11(18.64)$ & $1(7.69)$ & $16(13.22)$ \\
\hline None, $n(\%)$ & $2(4.08)$ & $10(16.95)$ & $2(15.38)$ & $14(11.57)$ \\
\hline Total, $n(\%)$ & $49(100)$ & $59(100)$ & $13(100)$ & $121(100.00)$ \\
\hline
\end{tabular}


Table 3 Post-harvest fish preservation practices used by fishers and aquaculture producers in Siavonga district

\begin{tabular}{|c|c|c|c|}
\hline & \multicolumn{3}{|l|}{ Category } \\
\hline & Artisanal fishery & Commercial fishery & $\overline{\text { Aquaculture production }}$ \\
\hline \multicolumn{4}{|l|}{ Preservation practice } \\
\hline Smoking, $n(\%)$ & $28(57.14)$ & $0(0.00)$ & $1(7.69)$ \\
\hline Chilling, $n$ (\%) & $14(28.57)$ & $5(8.47)$ & $9(69.23)$ \\
\hline Sun sun-drying, $n(\%)$ & $4(8.16)$ & $46(77.97)$ & $0(0.00)$ \\
\hline Freezing, $n(\%)$ & $3(6.12)$ & $8(13.56)$ & $3(23.08)$ \\
\hline Total, $n(\%)$ & $49(100.00)$ & $59(100.00)$ & $13(100.00)$ \\
\hline \multicolumn{4}{|l|}{ Alternative practice } \\
\hline Smoking, $n(\%)$ & $9(18.37)$ & $0(0.00)$ & $1(7.69)$ \\
\hline Chilling, $n(\%)$ & $11(22.45)$ & $6(10.17)$ & $2(15.38)$ \\
\hline Sun sun-drying, $n(\%)$ & $6(12.24)$ & $12(20.34)$ & $0(0.00)$ \\
\hline Freezing, $n(\%)$ & $23(46.94)$ & $41(69.49)$ & $10(76.92)$ \\
\hline Total, $n(\%)$ & $49(100.00)$ & $59(100.00)$ & $13(100.00)$ \\
\hline
\end{tabular}

were observing some regulations on product safety and quality control of which $25.00 \%$ observed internal regulations, another $25.00 \%$ observed external regulations, and $50.00 \%$ could not disclose the enforcer of their regulation.

The challenges related to post-harvest fish losses and preservation practices in Siavonga district are summarized in Table 6. As indicated, lack of cold storage facilities and unfavorable weather (sunny and windy) conditions were the major challenges faced by those involved in artisanal and commercial fisheries. For the aquaculture producers, poor road network to the market and unfavorable weather conditions were the major challenges related to post-harvest fish production activities.

\section{Discussion}

Post-harvest food losses remain a significant challenge affecting food production industries globally. These losses include physical, nutritional, or economic, and render a food product inaccessible or nutritionally poor for human consumption (Cheke and Ward, 1998; Obodai et al., 2009; Entee, 2015). In fisheries and aquaculture, these losses comprise material losses of harvested fish resulting from spoilage, grading, size breakage, bycatch discards, and operational losses (Tesfay and Teferi,
2017). In this study, we investigated fish post-harvest losses and preservation practices among those involved in the artisanal fishery, commercial fishery, and aquaculture production in Siavonga district along Lake Kariba. The study is the first of its kind to combine the three categories of players in Zambia's fisheries sector. Artisanal fishers usually operate in shallow waters close to the lakeshore. In Zambia, they are characterized by the use of gillnets and small fishing boats (locally known as banana boats) where fish species from the Cichlidae family are the main fish of interest. Commercial fishers are characterized by the use of fishing rigs operated in deep waters and usually, Tanganyika Sardine (Limnothrissa miodon) locally known as Kapenta is the main species of interest. Unlike artisanal and commercial fishers, aquaculture producers in Siavonga district raised their own fish mainly in cages with the invasive Nile tilapia (Oreochromis niloticus) being the main cultured species. According to Hobbs (1982), fish begin to spoil soon after harvest although the rate of spoilage vary depending on ambient conditions, fishing technology, fishing equipment, catching season, handling, and preservation activities. In the present study, all the artisanal and commercial fishers were experiencing some degree of post-harvest fish losses while the aquaculture producers did not report any post-harvest fish losses.

Table 4 Effectiveness of the fish preservation practices used in Siavonga district

\begin{tabular}{lllll}
\hline $\begin{array}{l}\text { Effectiveness of } \\
\text { commonly used } \\
\text { practice }\end{array}$ & Category & Commercial fishery & Aquaculture production & $\begin{array}{l}\text { Total, } n \\
(\%)\end{array}$ \\
\cline { 2 - 5 } Effective, $n(\%)$ & Artisanal fishery & $50(84.75)$ & $12(92.31)$ & $103(85.12)$ \\
Very effective, $n(\%)$ & $41(83.67)$ & $9(15.25)$ & $1(7.69)$ & $18(14.88)$ \\
Total, $n(\%)$ & $49(16.33)$ & $59(100)$ & $13(100)$ & $121(100)$ \\
\hline
\end{tabular}


Table 5 Safety and quality control of fish products in Siavonga district

\begin{tabular}{|c|c|c|c|c|c|}
\hline \multirow{2}{*}{\multicolumn{2}{|c|}{$\begin{array}{l}\text { Do you have product safety and } \\
\text { quality control regulation? }\end{array}$}} & \multicolumn{3}{|l|}{ Category } & \multirow{2}{*}{$\begin{array}{l}\text { Total, } n \\
(\%)\end{array}$} \\
\hline & & Artisanal fishery & Commercial fishery & Aquaculture production & \\
\hline \multicolumn{2}{|l|}{ No } & $26(53.06)$ & $39(66.10)$ & $5(38.46)$ & $70(57.85)$ \\
\hline \multicolumn{2}{|l|}{ Yes } & $23(46.94)$ & $20(33.90)$ & $8(61.54)$ & $51(42.15)$ \\
\hline \multicolumn{2}{|c|}{ Total, $n(\%)$} & $49(100)$ & $59(100)$ & $13(100)$ & $121(100)$ \\
\hline \multirow[t]{3}{*}{ Yes } & Internal (producer's own) & $6(26.09)$ & $4(20.00)$ & $2(25.00)$ & $12(23.53)$ \\
\hline & External (local authorities) & $5(21.74)$ & $2(10.00)$ & $2(25.00)$ & $9(17.65)$ \\
\hline & Others (unspecified) & $12(52.17)$ & $14(70.00)$ & $4(50.00)$ & $30(58.82)$ \\
\hline \multicolumn{2}{|c|}{ Total, $n(\%)$} & $23(100)$ & $20(100)$ & $8(100)$ & $51(100)$ \\
\hline
\end{tabular}

Our observation showed that the majority of the fishers (artisanal and commercial) did not have proper cold storage facilities to keep their fish soon after harvest. Moreover, some of them were covering long distances coupled with unfavorable weather (sunny and windy) conditions from their fish catching areas to the lake shore to meet the customers. It was further observed that the majority of the artisanal fishers had organized buyers within the district who would send their agents to the lakeshore to collect the fish as soon as it arrived from various landing sites. This promoted increased fish handling through quantifying and assessing the quality before taking it to the actual buyers which in turn led to increased quality deterioration. These factors were observed to be the major driving forces for increased losses among the fishers in Siavonga district. Moreover, in line with the findings of Akande and Diei-Ouadi (2010), it was revealed that post-harvest fish losses among these fishers occurred at all stages in the fish supply chain from capture to consumers. Contrary to the fishers, most aquaculture producers had better cold storage facilities where harvested fish was kept to prevent spoilage, and the time between harvesting and storage was usually minimal. This was probably due to the fact that aquaculture production in Siavonga district was dominated by large-scale commercial producers, such as Yalelo Limited and Lake Harvest Limited, operating in cages with appropriate harvesting technologies that were capable of minimizing or completely eliminating post-harvest losses. Similar findings were also reported by Hasimuna et al. (2019). These large-scale commercial producers use advanced technology during harvests, storage, and distribution of the fish to well-established selling points around the country. This leads to a significant reduction of time between fish harvesting, storage, and eventual delivery to the market consequently suggesting that the time taken between harvest and delivery to the market/ consumers was the major factor determining postharvest fish losses in the district.

Regarding the extent of post-harvest fish losses among the fishers in the district, the results showed that the majority were experiencing up to $10 \%$ fish losses per given total catch. This was lower than $20-40 \%$ losses encountered by the majority of the fishers in the neighboring United Republic of Tanzania and Uganda (Akande and Diei-Ouadi, 2010). Many factors, however, may be responsible for the variations observed in the estimated losses per catch, for example, the assessment methods used, catching season, targeted species, and fishery being assessed among others. The study further revealed that

Table 6 Major challenges encountered in fish post-harvest by the respondents (fishers and aquaculture producers) in Siavonga district

\begin{tabular}{|c|c|c|c|c|}
\hline \multirow[t]{2}{*}{ Challenge } & \multicolumn{3}{|l|}{ Category } & \multirow{2}{*}{$\begin{array}{l}\text { Total, } n \\
\text { (\%) }\end{array}$} \\
\hline & Artisanal fishery & Commercial fishery & Aquaculture production & \\
\hline Fish losses due to theft, $n(\%)$ & $1(2.08)$ & $5(8.47)$ & $1(7.69)$ & $7(5.9)$ \\
\hline Poor road network to the market, $n(\%)$ & $5(10.20)$ & $2(3.39)$ & $3(23.08)$ & $10(8.26)$ \\
\hline Lack of cold storage facilities, $n(\%)$ & $18(36.73)$ & $26(44.07)$ & $2(15.38)$ & $46(38.02)$ \\
\hline Competition on the market, $n(\%)$ & $2(4.08)$ & $2(3.39)$ & $2(15.38)$ & $6(4.96)$ \\
\hline Strict Government regulations, n (\%) & $3(6.12)$ & $1(1.69)$ & $1(7.69)$ & $5(4.13)$ \\
\hline Weather conditions, $n$ (\%) & $15(30.61)$ & $19(32.20)$ & $4(6.78)$ & $38(31.40)$ \\
\hline Others (unspecified) & $5(10.20)$ & $4(6.78)$ & $0(0.00)$ & $9(7.44)$ \\
\hline Total, $n(\%)$ & $49(100)$ & $59(100)$ & $13(100)$ & $121(100)$ \\
\hline
\end{tabular}


most losses especially for commercial fishers occurred during the rainy season when sunlight hours are unpredictable, an observation which was also made by FAO (2010) and Jim-Saiki et al. (2014). The fishers revealed that on average, Kapenta needed about 6 h to effectively cure when the sun is constantly shining. This was less time compared with the time reported by Akande and Diei-Ouadi, (2010) for similar species in Lake Victoria where 1 to 3 days were required. The differences, however, may be attributed to the seasons the fish was dried; for example, longer sun-drying time may be expected during rainy or winter months compared with the summer months. In order to minimize or where possible eliminate post-harvest fish losses, the fishers and aquaculture producers in the district were employing various strategies. Selling the fish quickly while still fresh to avoid or minimize quality deterioration was the most common strategy, represented by nearly half of the respondents, although quick processing was also an equally important strategy for the aquaculture producers. Similar findings were also reported in Uganda by Akande and Diei-Ouadi (2010). It should also be noted that this strategy may cost the producers due to desperation, which could lead to selling of fish at lower prices. However, such a problem was rarely encountered in Siavonga probably because the demand for fish was high, and sometimes, buyers were found waiting at landing sites. Overall, these results suggest that much of the losses encountered by the fishers in Siavonga district on Lake Kariba were not related to the effectiveness of the preservation practices used, but other factors, particularly the time between harvest and preservation. Therefore, inadequate ice during transportation, time it takes before fish is preserved after harvest, inadequate preservation facilities, and handling of fish before and after landing, maybe the major factors contributing to fish losses in the district.

In the present study, four major fish preservation practices (smoking, sun-drying, chilling, and freezing) were revealed in Siavonga district. In some cases, fishers could use two methods simultaneously, but the focus in this study was on the major practice. Similar to the findings of Tesfay and Teferi (2017), no use of chemical as fish preservation practice at any stage was reported in the present study. This can be attributed, generally, to the limited knowledge on both short- and long-term benefits and consequences of applying some chemicals on fish for preservation. Moreover, the application of chemicals in food is increasingly receiving public concerns with regard to food safety (Maulu et al., 2019). Smoking was the most commonly used preservation practice among the artisanal fishers in Siavonga district. Contrary to the findings of Onyango et al. (2017), most of the artisanal fishers reported that the traditional smoking kiln was the major tool used to smoke the fish because it was deemed cheaper, less time-consuming, and reduces microbial growth thereby giving fish long shelf life besides adding a nice flavor. However, our findings were in line with those reported by Akintola and Fatoya et al. (2017) among small-scale fishers in Nigeria. Caution was given by the fishers regarding the use of smoking for preserving fish since it requires proper monitoring to ensure a quality product. The majority of the commercial fishers were commonly used sun-drying as a preservation practice for their fish. This practice was considered cheapest and easiest of all the other methods since it entirely depended on sunshine. In line with the findings of Onyango et al. (2017), the caught fish were usually sundried by spreading it on the sun-drying racks made of poles and small meshed netting material, which accelerated the sun-drying process. Additionally, the use of sun-drying racks was preferred because it minimized contamination of the fish with external materials, such as sand which is a major problem when dried on the sand. However, although sun sun-drying was deemed the easiest and most commonly used practice among the commercial fishers, it had higher risks of fish losses as it depended on weather conditions (sunshine) which is quite unpredictable, especially during the rainy season. Owaga et al. (2009) and Kirema-Mukasa and Reynolds (1991) have also reported increased fish (L. miodon) losses during periods of unfavorable weather (sunshine) conditions. Moreover, in line with the findings of Akintola and Fatoya et al. (2017) and Akande and Diei-Ouadi (2010), increased quality deterioration of the fish for the commercial fishers occurred during periods of inadequate sunshine leading to poor drying of the fish. For the aquaculture producers, chilling was the most commonly used fish preservation practice in this study. This was attributed to the fact that their fish was often harvested in large quantities and quickly delivered to various selling points around the country. Moreover, the large commercial aquaculture producers in most cases were using large, mobile, and stationed cold room facilities where fish was stored immediately after harvesting to prevent spoilage. For some artisanal fishers, chilling was also used to prevent the fish from getting spoiled while moving from their fishing areas to the landing sites. This was often done by carrying large ice blocks in the boat as they go fishing. Freezing was also practiced by all respondents captured in the study but only as an alternative. It was only practiced when the commonly used ones were not accessible due to prevailing conditions at a particular time. For example, during rainy season smoking was not commonly practiced due to difficulties in collecting wood and controlling the heat, as such most of the fishers resorted to freezing the fish as the only alternative. For the aquaculture producers, 
freezing was only opted for in case of delayed transportation of the fish to their selling points around the country.

Food safety and quality control is a critical element of food production that determines the protection of public health, economic development, social stability, and protecting a country's image and food security. In Zambia, generally, fish safety and quality control among the various producers are poorly reported. In this study, the majority of the fishers were not observing any regulation regarding fish product safety and quality control. However, for the aquaculture producers, the majority were observing some regulations. This is probably because fish from most aquaculture producer in Siavonga is transported to almost all parts of the country for consumption and, hence, the need to be accountable for their products. Interesting to note in this study was that the majority of those that indicated they were observing some fish product safety and quality control across the different categories did not disclose the source or body enforcing the regulations. The failure to disclose the source of control measures may be attributed to fear of facing repercussions in the case they did not have any regulation or the measures employed were below the accepted standards outlined by the national guidelines. Moreover, it was observed during the survey that the quality of fish was not taken into consideration by the producers when pricing, particularly at landing sites. The price was rather based on the weight, suggesting that additional losses were recorded by the buyers towards the end of the supply chain. Similar observations were reported by Akande and Diei-Ouadi (2010) on Lake Victoria. How much of the losses are further encountered towards the end of the supply chain remain an area that require further investigations as it was beyond the scope of this study.

The current gap existing between fish supply and demand globally is not likely to be filled anytime soon, especially in developing countries. Moreover, the gap is likely to further increase due to many factors that include human population increase, post-harvest fish losses, unsustainable wild fish harvests, and environmental-related concerns, for example, water pollution and climate change. Therefore, minimizing or completely eradicating fish post-harvest losses may significantly contribute to the efforts of reducing the gap between global fish supply and demand. In the present study, several challenges affecting post-harvest fisheries activities in Siavonga district were reported. Lack of cold storage facilities was the major challenge affecting both the artisanal and commercial fishers, while poor road network was the major challenge for the aquaculture producers. Similar findings were reported by Tesfay and Teferi (2017); FAO, (2008); Kabahenda et al., (2009). The reasons for indicating a lack of cold storage facilities as a major challenge by the fishers could be due to lack of a public cold storage facility in the district. Meaning that the fishers have to depend on own or rented facilities that may lead to them incurring higher costs especially during times of electricity power cuts. These results could also provide justification why the majority of the artisanal and commercial fishers commonly used smoking and sun-drying respectively as preservation practices. Poor rood network to the market was reported as the major challenge for the aquaculture producers. This may be due to the fact that most of these producers transport their fish to almost all other parts of the country, unlike the fishers who found customers at the shore of the lake waiting to buy the fish as soon as they landed. Another considerable percentage of the fishers indicated that changes in weather conditions which included mostly sunlight and water waves. For the aquaculture producers, another good percentage indicated that competition on the market was another challenge for some aquaculture producers. This may have been selected by some small aquaculture producers mainly producing fish in ponds contrary to those producing in cages on a commercial scale. Hence, it is difficult for them to compete with commercial producers in the same district.

\section{Conclusions}

Improvements in fish post-harvest practices are very crucial for minimizing post-harvest fish losses, and the everincreasing gap between fish supply and demand. The present study has investigated the status of post-harvest fish losses and preservation practices in Siavonga district. This information is very crucial in the efforts that seeks to promote food security through sustainable fisheries and aquaculture production. The study has revealed that both artisanal and commercial fishers in the district were affected by post-harvest fish losses which presents a threat to national food security. Interestingly, however, no postharvest fish losses were reported by the aquaculture producers. Lack of cold storage facilities and changing weather conditions were the two major factors that contributed to post-harvest fish losses among the fishers, while poor road network and competition on the market were the major challenges faced by the aquaculture producers in the district. The study further revealed that fish product safety and quality control were poorly observed in the district. Therefore, introducing innovative and lowcost technology, self-development skills in fishing communities, more and better cold facilities, and ensuring strict observance of product safety and quality control measures could help reduce post-harvest fish losses and guarantee public health in Siavonga district. 


\section{Acknowledgements}

The authors would like to thank the Zambian Department of Fisheries in Siavonga district for facilitating data collection which enabled the successful carrying out of the study. Finally, the authors sincerely thank Mr. Mwaanda Sikanyenyene who tirelessly rendered a helping hand during data collection.

\section{Authors' contributions}

SM generated the research idea, designed the study, participated in data collection, and wrote the manuscript; OJH participated in study design, data collection, writing of the manuscript, and editing; CM participated in manuscript writing, editing, and results interpretation, while MM participated in data analysis and interpretation of the results. All the authors read and approved the final manuscript.

\section{Funding}

This work did not receive any special funding.

\section{Availability of data and materials}

The authors declare that all the supporting data and materials used in this study are presented sufficiently in the tables and figures.

\section{Ethics approval and consent to participate}

Not applicable

\section{Consent for publication}

Not applicable

\section{Competing interests}

The authors declare that they have no competing interests.

\section{Author details}

${ }^{1}$ Centre for Innovative Approach Zambia (CIAZ), Lusaka, Zambia. ${ }^{2}$ Wuxi Fisheries College, Nanjing Agricultural University, Wuxi, China. ${ }^{3}$ National Aquaculture Research and Development Centre (NARDC), Mwekera, Kitwe, Zambia. ${ }^{4}$ Kapasa Makasa University Campus, Department of Agriculture and Aquatic Sciences, The Copperbelt University, Chinsali, Zambia.

Received: 10 February 2020 Accepted: 20 August 2020

Published online: 30 September 2020

\section{References}

Akande G, Diei-Ouadi Y. Post-harvest losses in small-scale fisheries: case studies in five sub-Saharan African countries. In: FAO fisheries and aquaculture technical paper. No. 550. Rome: FAO; 2010. 72p.

Akintola SL, Fatoya KA. Small-scale fisheries in the context of traditional postharvest practice and the quest for food and nutritional security in Nigeria, review. Agriculture and Food Security. 2017. https://doi.org/10.1186/s40066017-0110-z

Cheke RA, Ward AR. A model for evaluating interventions designed to reduce post-harvest fish losses. Fish Res. 1998;35(3):219-27.

Entee S. Post-harvest processing value chain literature review report. In: The USAID/Ghana sustainable fisheries management project (SFMP). Narragansett, RI: Coastal Resources Center, Graduate School of Oceanography, University of Rhode Island and SNV Netherlands Development Organization; 2015.

FAO. Bulletin of Fishery Statistics, No. 35. Rome, Food and Agriculture Organization, 2004. Found at: http://www.fao.org/fi/fifacts/plots/Region/ wbyreg5.asp. Accessed 18 Oct 2017.

FAO. Securing regional supply in aquatic products: prospects from the FAO postharvest loss assessment case studies, in Committee for Inland Fisheries and Aquaculture of Africa, Fifteenth Session. Lusaka, Zambia, 2008.

FAO. Reducing post-harvest losses, FAO Fisheries and Aquaculture Department, 2010.

FAO. The state of world fisheries and aquaculture 2018: contributing to food security and nutrition for all, Rome, 2018.

Getu A, Misganaw K, Bazezew M. Post-harvesting and major related problems of fish production. Fish Aquac J. 2015;6:154.

Global Fish Alliance [GFA]. The importance of capture fisheries for food security in Zambia, 2007.

Hasimuna OJ, Maulu S, Monde C, Mweemba M. Cage aquaculture production in Zambia: assessment of challenges and opportunities in Lake Kariba, Siavonga district, Egyp J of Aqu Res 2019,https://doi.org/https://doi.org/10.1016/j.ejar. 2019.06.007.

Hobbs G. Changes in fish after catching: fish handling and processing, Torry, 1982.

Jim-Saiki LO, Alhaji TA, Giwa JE, Oyerinde M, Adedeji AK. Factors constraining artisanal fish production in the fishing communities of Ibeju-Lekki local government area of Lagos state. Int J Innov Res Dev. 2014;3(13):97-101.

Kabahenda MK, Omony P, Hüsken SMC. Post-harvest handling of low-value fish products and threats to nutritional quality: a review of practices in the Lake Victoria region, The Worldfish Center, Project Report, 2009.

Kirema-Mukasa CT, Reynolds JE. Marketing and consumption of fish in Uganda, in FAO, Fisheries and Aquaculture Department, Project Reports, 1991.

Kitinoja L. Innovative approaches to food loss and waste issues, frontier issues, brief submitted to the Brookings Institution's ending rural hunger project; 2016.

Lokuruka MNI. Food quality perspectives in African fish products: practices, challenges and prospects. Int J Fish Aquacult Scies. 2016;2248-9975:5-32

Maulu S, Munganga BP, Hasimuna OJ, Haambiya LH, Seemani B. A review of the science and technology developments in Zambia's aquaculture industry. J Aquac Res Development. 2019;10:567.

Maulu S, Musuka CG. Assessing the abundance and distribution of tilapia species in Lake Kariba, Int. J. of Fish. Aquac. Sci. (IJFAS), IRPH, 2018, 8:1, pp. 1-11.

Obodai EA, Muhammad BA, Obodai GA, Opoku E. Effect of fuel wood on the quality of smoked freshwater fish species sold in the tamale central market, northern region of Ghana. Ethio J Env Stu Mgmt. 2009;2:2.

Onyango DM, et al. Evaluation of fish processing and preservation systems along the shores of Lake Victoria towards enhancement of sun sun-drying technology. Int J Food Sci Nutr Eng. 2017;7(5):111-8.

Owaga EE, Onyango CA, Njoroge CK. Effect of selected washing treatments and sun-drying temperatures on biochemical and microbiological quality of dagaa (Rastrineobola argentea). Afr J Food Agric Nut Develop. 2009;9:830-45. Subasinghe RP. FAO Aquaculture Newsletter, FAN 54 Invited Editorial, 2016.

Tesfay S, Teferi M. Assessment of fish post-harvest losses in Tekeze dam and Lake Hashenge fishery associations: northern Ethiopia, Agric \& Food Secur. 2017.

Ward A, Signa D. Reducing post-harvest fish losses for improved food security, SMARTFISH Programme, 2017.

\section{Publisher's Note}

Springer Nature remains neutral with regard to jurisdictional claims in published maps and institutional affiliations.

\section{Ready to submit your research? Choose BMC and benefit from:}

- fast, convenient online submission

- thorough peer review by experienced researchers in your field

- rapid publication on acceptance

- support for research data, including large and complex data types

- gold Open Access which fosters wider collaboration and increased citations

- maximum visibility for your research: over $100 \mathrm{M}$ website views per year

At $\mathrm{BMC}$, research is always in progress.

Learn more biomedcentral.com/submissions 